\title{
Valorization of Toxic Weed Lantana camara L. Biomass for Adsorptive Removal of Lead
}

\author{
Vipin Kumar Saini, ${ }^{1}$ Surindra Suthar, ${ }^{1}$ Chaudhari Karmveer, ${ }^{1}$ and Kapil Kumar ${ }^{2}$ \\ ${ }^{1}$ School of Environment \& Natural Resources, Doon University, Dehradun, Uttarakhand 248001, India \\ ${ }^{2}$ Department of Environmental Engineering, National Institute of Technology, New Delhi 110040, India \\ Correspondence should be addressed to Surindra Suthar; suthariitd@gmail.com
}

Received 12 October 2016; Revised 11 January 2017; Accepted 24 January 2017; Published 26 February 2017

Academic Editor: Daryoush Afzali

Copyright @ 2017 Vipin Kumar Saini et al. This is an open access article distributed under the Creative Commons Attribution License, which permits unrestricted use, distribution, and reproduction in any medium, provided the original work is properly cited.

\begin{abstract}
Valorization of Lantana camara L., which is a recognized invasive plant, as a potential source of activated carbon is proposed in this study. Its stem and leaf have been utilized for the preparation of activated carbon (ACL and ACS) by following acid-impregnation technique, followed by thermal treatment. The developed activated carbon samples were characterized for their structural and surface related properties by low-temperature nitrogen adsorption isotherm, $\mathrm{SEM}$ techniques, and $\mathrm{pH}_{\mathrm{PZC}}$ method. The samples show reasonable high surface area and pore volume; nonetheless, these properties are higher in case of ACL as compraed to ACS. Both of these samples developed negative charge on their surface due to acid treatment that resulted in an increase in adsorption at $\mathrm{pH}>5$. The batch adsorption studies on these samples shows the $\mathrm{Pb}$ (II) ion adsorption capacities of ACL and ACS were 36.01 and $32.24 \mathrm{mg} \cdot \mathrm{g}^{-1}$, respectively, at $25^{\circ} \mathrm{C}$. The kinetics of adsorption with both the sample systems follow the pseudo-second-order model, whereas the experimental equilibrium isotherm data of ACL and ACS were explained by Freundlich and Langmuir models, respectively. For these samples, the $\mathrm{HCl}$ shows maximum desorption with which the recycling test on these samples shows that ACS has better recycling potential over ACL samples.
\end{abstract}

\section{Introduction}

Lantana camara is a flowering plant that belongs to Verbenaceae family and is often planted in gardens. It is native to Central and South America and spread to around more than 40 different countries [1], where now it has become an invasive species [2]. It was brought by Dutch explorers to Europe from America, where it was cultivated widely and soon it spread into Asia and other countries, where it became the world's most notorious weed. It grows impassable thickets which suppress the growth of native species. Its growth often competes with, suppresses, and crowds out more desirable species, which leads to a loss of plant diversity, in affecting the area. Other problems with this species include its toxicity to livestock and if it invades agricultural land it may cause a decrease in productivity [3]. In India, Australia, and South Africa, it is widespread occupying millions of hectares of land [1]. There is a quest if we can fight the spread of invasive species or we need to develop strategies for their adaptive management.

According to literature, its spread is being controlled by several methods on a large scale, including mechanical (stickraking, bulldozing, plowing, and grubbing), chemical (using fluroxypyr and glyphosate), and biological methods (using different bug, beets, and seed-feeding fly) [4]. Use of this plant for a pollution abatement technique would be a most cost-effective management tool, in its control. One of the possible uses of converting this biomass into applicable materials is shown in [2]. One way of its valorization could be its use in environmental applications like wastewater treatment.

Among various technologies to treat industrial wastewater, the adsorption is an established technique for its efficiency and cost of operation. In adsorption technique, an extremely porous material (adsorbent) is used, which selectively adsorb the impurities from the aqueous phase by noncovalent 
bonding ( $\mathrm{H}$-bond, electrostatic bonding, and coordination bonding) [5]. The key challenge in the use of adsorption technique for water treatment applications is the cost of adsorbent. Activated carbon is a well-known adsorbent particularly due to its microporous structure and high surface area. It is prepared from a variety of carbonaceous sources like nutshells, coconut husk, peat, coir, lignite, coal, and wood. Physical or chemical activation processes are generally used for its development. The cost of activated carbon depends upon the choice of the process as well as the price of starting carbonaceous material (raw material) $[5,6]$. So far, numerous plant materials and agricultural, industrial wastes have been explored for the development of activated carbon and their application in water treatment. But, surprisingly, there were no such studies on invasive weeds in general and Lantana camara in particular. Only recently have few researchers started to investigate its use as a source of activated carbon and study its potential for removal of water pollutants. But these studies show limited adsorption capacity and are limited to dyes [7] and phenol [8]. In this context, it is apparent that if processed and activated suitably, this Lantana camara L. can become a potential source of activated carbon, and this can valorize its biomass for adsorptive removal of water pollutants.

Like many other heavy metals, lead is also toxic and known for bioaccumulation that affects various body systems and is predominantly unsafe to young children [9]. It comes into water through the combustion of fossil fuels and the smelting of sulfide ore and into lakes and streams by acid mine drainage. Process industries, such as battery manufacturing and metal plating and finishing, are also a prime source of lead pollution [10]. Lead accumulates mainly in bones, brain, kidney, and muscles and may cause many serious disorders like anemia, kidney disease, nervous disorders, and sickness and even death. There is no known level of lead exposure that is considered safe. Current EPA drinking water standard for lead is $0.05 \mathrm{ppm}$, but a level of $0.02 \mathrm{ppm}$ has been proposed and is under review [11].

In this study, leaves and stem of Lantana camara L. were used to prepare activated carbon by chemical activation method. The developed carbon was characterized by its structural and surface properties. The adoptions potentials of both the prepared materials were studied compared with selective adsorption of lead from aqueous solutions. The isotherm and kinetic modeling were used to explore adsorption behavior of these materials. Sustainability of optimized material in adsorption application was investigated in the light of their reusability in different adsorption cycle. To the best of our knowledge, this is the first study where an invasive weed like Lantana camara L. has been used as a precursor for activated carbon and used for adsorptive removal of pollutants.

\section{Experimental}

2.1. Materials. All chemicals used in this work were of analytical grade and were purchased from Merck (India). The solutions were prepared by using deionized water. Analytical grade lead nitrate $\left(\mathrm{Pb}\left(\mathrm{NO}_{3}\right)_{2}\right), 99 \%$ pure, was used to prepare a lead solution. All the experiments were conducted at a constant temperature of $25 \pm 0.1^{\circ} \mathrm{C}$ unless otherwise specified.

2.2. Adsorbent Preparation. The leaves and stems samples of Lantana camara were collected locally, from the premises of Doon University, Dehradun. To remove dirt particles from leaves and stems, it was washed several times with tap water and then in the end with double distilled water. The washed samples were air dried, followed by drying in a hot air oven for 24 hours at $80^{\circ} \mathrm{C}$. The dried samples were shredded and then crushed to powdered form. For chemical activation, the method was adopted from literature [12]. In this method, the dried powders of sample were mixed with concentrated $\mathrm{H}_{2} \mathrm{SO}_{4}$ (Lantana leaves or stem: $\mathrm{H}_{2} \mathrm{SO}_{4}$ ratio; $1: 1.5 \mathrm{w} / \mathrm{v}$ ) and were kept at $200^{\circ} \mathrm{C}$ for $24 \mathrm{~h}$. The chemically burned (carbonized) samples were then washed several times with distilled water to remove any free acid and were then soaked overnight in $1 \%$ sodium bicarbonate solution to remove any residual acid from pores. The material then was again washed twice with distilled water and dried in hot air oven at $105^{\circ} \mathrm{C}$. The dried samples were then finely ground and sieved to get a particle size of $150 \mu \mathrm{m}$. The as-prepared samples of activated carbon from leaves and stem were labeled as ACL and ACS, respectively, and stored in desiccators until required.

2.3. Adsorbent Characterization. The morphological structure of the prepared carbon samples was observed by means of scanning electron microscopy (SEM) using a ZEISS EVO Series Microscope EVO 50. BET surface areas of samples were measured by liquid nitrogen adsorption method at $77 \mathrm{~K}$ using Micromeritics ASAP 2020. To characterize the surface charge of adsorbent, the experiment of the point of zero-charge $\mathrm{pH}_{\mathrm{zpc}}$ was carried out. The methodology for determination of $\mathrm{pH}_{\mathrm{zpc}}$ was adopted from an earlier study [13]. For this purpose, $0.025 \mathrm{~g}$ of adsorbent sample was kept in contact with $25 \mathrm{~mL}$ of a solution under 11 different $\mathrm{pH}$ conditions $(2,3,4,5$, $6,7,8,9,10,11$, and 12) adjusted with solutions of $0.1 \mathrm{M} \mathrm{NaOH}$ or $\mathrm{HNO}_{3}$. The samples were kept stirring on a water bath at $25^{\circ} \mathrm{C}$. After this step, the $\mathrm{pH}$ of each solution was measured and a plot of the initial $\mathrm{pH}$ versus the final $\mathrm{pH}$ was obtained. From this plot, the $\mathrm{pH}$ at which the values of initial and final $\mathrm{pH}$ are found identical is testified as $\mathrm{pH}_{\mathrm{PZC}}$, the point of zero charge.

2.4. Adsorption Studies. Several parameters individually influence the adsorption properties of a given adsorbent. It is, therefore, essential to study the variation in the amount of adsorption as a function of the different parameter, like time, $\mathrm{pH}$, temperature, and adsorbate (lead ion in the present case) concentration. The effect of $\mathrm{pH}$ on $\mathrm{Pb}$ (II) ion concentrations in solutions without adsorbent was also examined so as to evaluate the attribution of precipitation to the sorption process. Thereafter the \% precipitation was deducted from total removal present to calculate the correct $\%$ adsorption amount. The adsorption studies were performed in the form of batch experiments. The samples obtained from batch adsorption experiments were filtered through Millipore SLHN033NB Millex HN Syringe Filter 
with Nylon Membrane $(0.45 \mu \mathrm{m})$ and analyzed by iCE ${ }^{\mathrm{TM}} 3300$ AAS Atomic Absorption Spectrometer. The adsorbed amount was calculated with the following mass balance equation, where $q_{e}$ is the amount of adsorption $\left(\mathrm{mg} \cdot \mathrm{g}^{-1}\right), C_{0}$ and $C_{e}$ are the initial and equilibrium concentrations $\left(\mathrm{mg} \cdot \mathrm{L}^{-1}\right), m$ denotes the mass $(\mathrm{g})$ of adsorbent, and $V$ is volume $(\mathrm{mL})$ of adsorbate solution.

$$
q_{e}=\frac{\left(C_{0}-C_{e}\right) V}{m \times 1000}
$$

The equilibrium time of adsorption was observed with both the adsorbents. For this, $2.5 \mathrm{~g}$ of sample was added to $500 \mathrm{~mL}$ lead solution $200 \mathrm{mg} \cdot \mathrm{L}^{-1}$ in a conical flask. The solution was stirred with a magnetic stirrer in a water bath at $25^{\circ} \mathrm{C}$. Periodically, the aliquots of $3 \mathrm{~mL}$ were sampled from this flask, up to $4 \mathrm{~h}$. The effect of $\mathrm{pH}$ on the adsorption was studied by adjusting the $\mathrm{pH}$ of the lead solution from 2 to 12 , using $0.1 \mathrm{M} \mathrm{NaOH}$ or $\mathrm{HCl}$ solutions. To study the effect of temperature on adsorption the batch adsorption experiments on two temperatures 25 and $45^{\circ} \mathrm{C}$ were carried out.

2.5. Adsorption Isotherms. The mechanism of adsorption in terms of adsorbate-adsorbent interaction and maximum adsorption capacity can be explored with the help of adsorption isotherms. These isotherms are characterized by certain constants and describe the mathematical relationship between the amount of adsorbate adsorbed per unit mass of adsorbent and the equilibrium concentration of adsorbate in the solution. For this study, $\mathrm{Pb}$ (II) solutions (each $100 \mathrm{~mL}$ ) of different concentration ranging from 50 to $500 \mathrm{mg} \cdot \mathrm{L}^{-1}$ were stirred with $0.5 \mathrm{~g}$ of adsorbents until equilibrium adsorption time, after which the samples were collected, filtered, and analyzed by AAS to determine $C_{e}$ and $q_{e}$. To observe an adsorption isotherm for a given adsorbent-adsorbate system, $q_{e}$ are plotted as a function of $C_{e}$. Then different mathematical models of adsorption were applied to these isotherms and compared for better fitting [14]. In this study, nonlinear models of Langmuir (see (2)) and Freundlich (see (3)) were applied.

$$
\begin{aligned}
& q_{e}=\frac{q_{\max } \cdot b \cdot C_{e}}{1+b \cdot C_{e}}, \\
& q_{e}=K_{f} \cdot C_{e}^{1 / n} .
\end{aligned}
$$

In these equations, $q_{\max }$ and " $b$ " are the Langmuir constants that denote maximum adsorption potential and equilibrium constant. Similarly, $K_{f}$ and " $n$ " are the Freundlich constant pertaining to the adsorption capacity and adsorption intensity, respectively.

2.6. Adsorption Kinetics. The adsorption kinetics were investigated with the help of contact time data. This data shows the progress of adsorption ( $\mathrm{mg} \cdot \mathrm{g}^{-1}$ ) with respect to contact time, $t$ (min). This kinetic data was then fitted to linear models of the pseudo-first-order (see (4)), pseudo-second-order (see
(5)), and intraparticle diffusion (see (6)) models $[15,16]$. The linear forms of these equations are expressed as follows:

$$
\begin{aligned}
\log \left(q_{e}-q\right) & =\log q_{e}-\frac{k_{1}}{2.303} t, \\
\frac{t}{q} & =\frac{1}{k_{2} q_{e}^{2}}+\frac{1}{q_{e}} t, \\
q & =k_{\mathrm{id}} t^{0.5}+C,
\end{aligned}
$$

where $q$ is the amount of adsorption at any time $(t, \min ), k_{1}$ $\left(\mathrm{min}^{-1}\right)$ is the pseudo-first-order adsorption rate constant, $k_{2}$ $\left(\mathrm{g} \cdot \mathrm{mg}^{-1} \cdot \mathrm{min}^{-1}\right)$ is the pseudo-second-order adsorption rate constant, $k_{\text {id }}\left(\mathrm{mg} \cdot \mathrm{g}^{-1} \cdot \mathrm{min}^{-1 / 2}\right)$ is the intraparticle diffusion rate constant, and $C\left(\mathrm{mg}^{-1} \mathrm{~g}^{-1}\right)$ is a constant in the intraparticle diffusion model that reflects the significance of the boundary layer on mass transfer effect.

2.7. Evaluation of Desorption Using Different Desorbing Solvents. Desorption of adsorbed metal from the surface of adsorbent is necessary for the sake of recovery of metal as well as reuse of adsorbent. For this purpose, different desorbent solutions were tested. In this experiment, the assay was prepared in two steps. In the first step, $0.5 \mathrm{~g}$ of activated carbon was stirred with $100 \mathrm{~mL}$ of $200 \mathrm{mg} \cdot \mathrm{L}^{-1} \mathrm{~Pb}$ (II) solution at $25^{\circ} \mathrm{C}$ up to equilibrium time. In the end, the AC samples were collected by filtration on a glass filter, washed with distilled water, and placed in an oven for $6 \mathrm{~h}$ at $60^{\circ} \mathrm{C}$. The filtrate was analyzed to observe $C_{e}$. In the next step, the dry AC samples were placed in contact with $100 \mathrm{~mL}$ of different solution independently, like $0.1 \mathrm{M} \mathrm{HNO}_{3}, \mathrm{HCl}, \mathrm{H}_{3} \mathrm{PO}_{4}, \mathrm{NaCl}$, and distilled water for $6 \mathrm{~h}$ on a magnetic stirrer in a water bath at $25^{\circ} \mathrm{C}$. The liquid phase was filtered through membrane filters and analyzed for desorbed $\mathrm{Pb}$ (II) ion concentration. The desorbed percentage was determined according to (7). The solution which achieves the maximum percentage of $\mathrm{Pb}$ (II) desorption from the loaded adsorbent was identified and used in successive adsorbent reuse test.

$$
\% \text { desorbed }=\frac{\text { amount desorbed }}{\text { amount adsorbed }} \times 100 .
$$

2.8. Adsorbent Reuse Test. The reusability is critical for the cost-effectiveness of a new adsorbent [27]. The reuse assay was performed in cycles, starting with the adsorption and ending with the desorption of the $\mathrm{Pb}$ (II) ions using identified desorbing solvent. After each cycle, the mass of AC samples was washed with distilled water and dried in an oven at $80^{\circ} \mathrm{C}$ for $2 \mathrm{~h}$. Four cycles were conducted with the same mass of AC samples.

\section{Results and Discussions}

3.1. Textural and Structural Characterization. Both the samples of prepared activated carbon were characterized for their surface and other adsorption related physicochemical properties. Porosity and surface area of prepared activated carbon samples were assessed by nitrogen adsorption at 


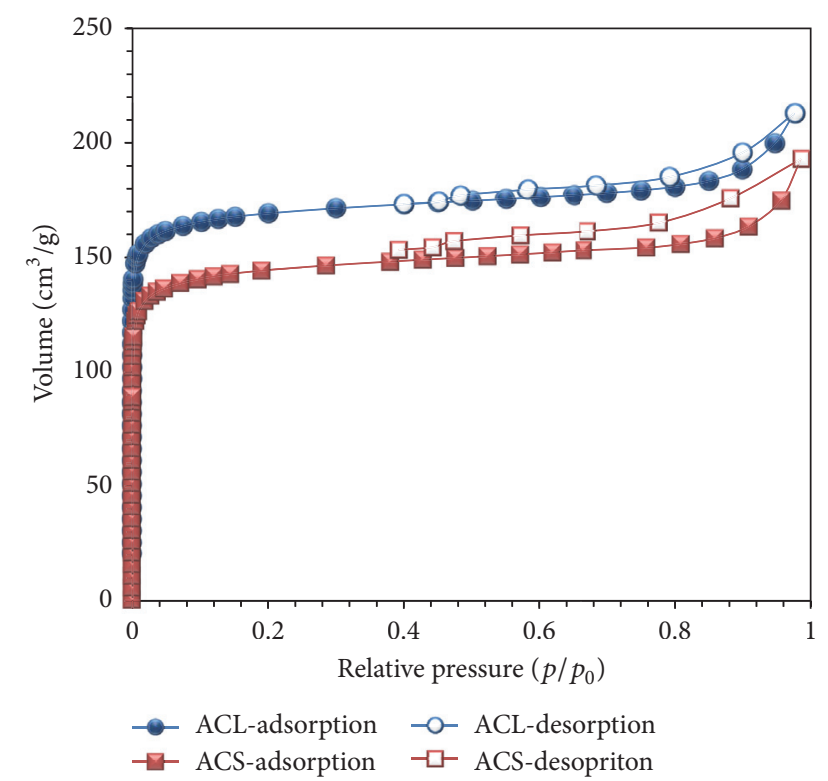

FIGURE 1: Low-temperature nitrogen adsorption isotherms, at $-196^{\circ} \mathrm{C}$, obtained from ACL and ACS samples.

$-196^{\circ} \mathrm{C}$ (Figure 1). The isotherm of activated carbon prepared from leaf (ACL) as well as stem (ACS) shows similar shape, which is of type I and slightly type IV with H1 loop, which are the characteristics of micro- and mesoporous materials [28]. Both the isotherms have slow condensation step at a relative pressure $\left(p / p_{0}=0.8-0.99\right)$ which corresponds to the capillary condensation of $\mathrm{N}_{2}$ within uniform mesopores. These results show the essential micro- and mesoporous nature of the prepared activated carbon samples. However, a decrease in adsorption amount in ACS sample is noted, as compared to ACL sample. From $\mathrm{N}_{2}$ adsorption data the specific surface area, $A_{\mathrm{BET}}$, was determined through BET model (within $p / p_{0}$ $0.05-0.15)$ [29]; likewise the micropore volume $V_{\text {micro }}$ and total pore volume $V_{\text {total }}$ of the materials are listed in Table 1. The anatomical differences in leaves and stem give rise to a change in their structural composition. The same difference has been translated into their surface area and pore volume properties after activation. The specific surface areas of ACL and ACS are 634 and $523 \mathrm{~m}^{2} / \mathrm{g}$, respectively. It is evident that chemical activation has produced large numbers of new pores in the samples by continuous devolatilization of the char and carbon burn-off. The dried leaves contain spongy mesophyll as compared to cortex and pith in the stem [30]. The total pore volume of ACL is higher compared to ACS; both the activated carbon samples are microporous in nature which is confirmed by fraction of their micropore volume with respect to their total pore volume.

SEM technique has been used to observe the change in samples morphology, before and after the treatment. The changes can be observed in Figure 2, where SEM images of raw materials (Lantana leaf and stem dust) are compared with, respectively, activated carbons (ACL and ACS). The surface of leaf sample seems uniform before activation and after activation it shows emergence of porous structure on
TABLE 1: The surface properties of prepared activated carbon samples obtained from low-temperature nitrogen adsorption isotherm data.

\begin{tabular}{lccc}
\hline Sample & $\begin{array}{c}\text { Specific Surface } \\
\text { area } A_{\text {BET }} \\
\mathrm{m}^{2} / \mathrm{g}\end{array}$ & $\begin{array}{c}\text { Total pore } \\
\text { volume } V_{\text {total }} \\
\mathrm{cm}^{3} / \mathrm{g}\end{array}$ & $\begin{array}{c}\text { Micropore } \\
\text { volume } V \mu \\
\mathrm{cm}^{3} / \mathrm{g}\end{array}$ \\
\hline $\mathrm{ACL}$ & 634 & 0.31 & 0.22 \\
$\mathrm{ACS}$ & 523 & 0.26 & 0.19 \\
\hline
\end{tabular}

the surface. Likewise, the stem sample surface also shows variation before and after activation; however, this variation is not as noticeable as in the case of leaves sample. It is likely due to the variation in the biochemical composition of leaves and stem [31]. In brief, it is evident from the SEM images that the surface of raw materials gets changed after acid treatment, though the extent of change is different for each sample.

In the chemical as well as physical activation method, the variation in original chemical composition resulted in the difference in surface functionality, because different compounds present in the surface and matrix of the sample give rise to different charge group (cationic or anionic) on the surface after carbonization and activation [32]. To observe this phenomenon in the context of the present samples $\mathrm{pH}_{\mathrm{PZC}}$ analysis has been carried out and the results are presented in Figure 3. It shows that $\mathrm{pH}_{\mathrm{PZC}}$ is approximately 5.0 for both the samples, which means at $\mathrm{pH}>5.0$ the activated carbons would have predominantly a negative charge at the surface while below this value the surface is positively charged. Typically, the $\mathrm{pH}$ at the point of zero charges on activated carbon is approximately $7[33,34]$. However, this was not observed from the AC samples prepared in the present study. The value of 5.0 can be explained by acid treatment to raw material which was used to prepare activated carbon. The $\mathrm{H}^{+}$ ions present on the surface after treatment will be released into the solution which resulted in lowering of $\mathrm{pH}$. The adsorption of cations, such as metal ions, is favored at $\mathrm{pH}$ $>\mathrm{pH}_{\mathrm{PZC}}$ while the adsorption of anions is favored at $\mathrm{pH}$ $<\mathrm{pH}_{\mathrm{PZC}}[35,36]$. Thus, the lead adsorption process should be carried out at $\mathrm{pH}$ equal to or greater than 5.0, to identify the optimal $\mathrm{pH}$ range.

3.2. Effect of Contact Time. The effect of contact time on the amount of adsorption by ACL and ACS is shown in Figure 4. It was observed that after more than $3 \mathrm{~h}$ at $25^{\circ} \mathrm{C} \mathrm{ACL}$ and ACS adsorb approximately $90 \%$ and $81 \%$, respectively, from $200 \mathrm{mg} \cdot \mathrm{L}^{-1} \mathrm{~Pb}(\mathrm{II})$ solution. It also shows the maximum adsorption capacity of ACL and ACS as 36.3 and $32.2 \mathrm{mg} \cdot \mathrm{g}^{-1}$, respectively. Beyond $3 \mathrm{~h}$ up to $24 \mathrm{~h}$, there was a small variation $<2 \%$ in the remaining concentration of $\mathrm{Pb}(\mathrm{II})$, which indicate adsorption equilibrium point. Hence, a minimum contact time of $3 \mathrm{~h}$ was adopted in all the subsequent tests. The data shows that $>50 \%$ of adsorption takes place in the initial 15 mins. During initial 10 mins of adsorption both ACS and ACL show the same rate of adsorption, but, subsequently, the rate of ACS system gets slightly slower compared to ASL system. This is possibly due to the higher surface area in the 


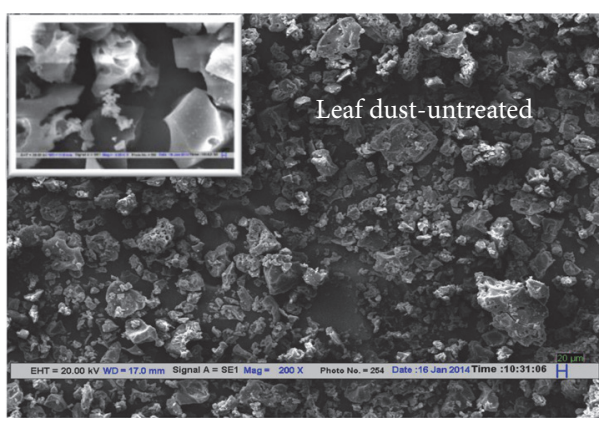

(a)

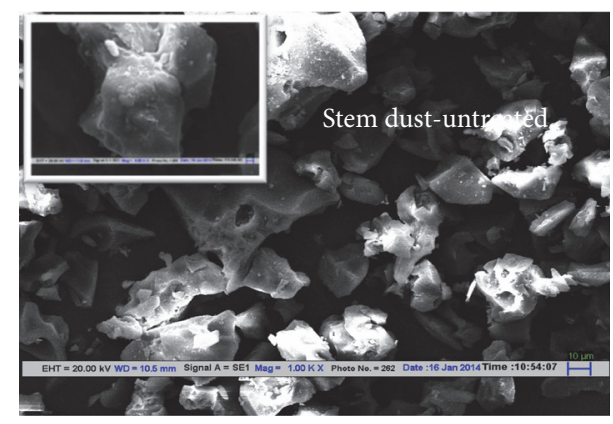

(c)

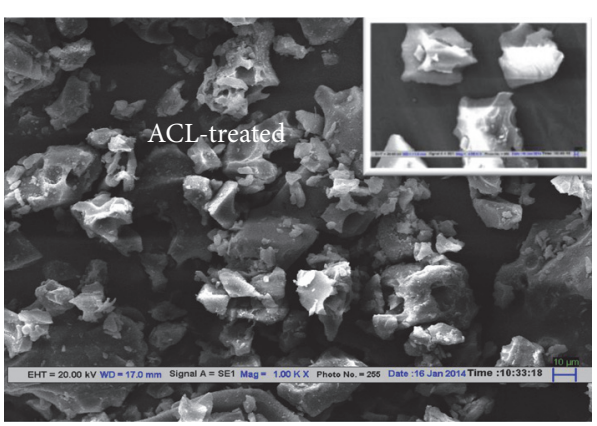

(b)

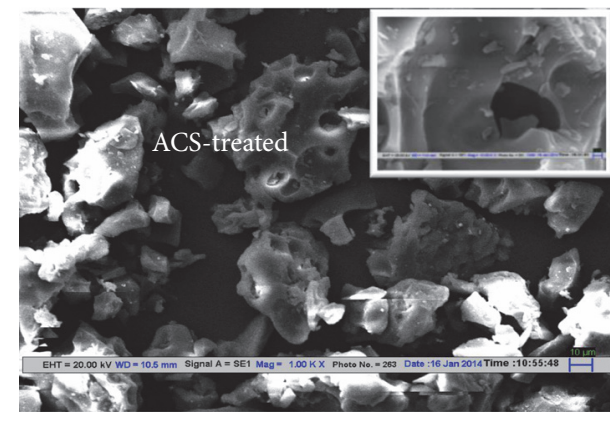

(d)

FIGURE 2: SEM images of different magnification of L. camara (stem and leaves) samples before and after acidic treatment.

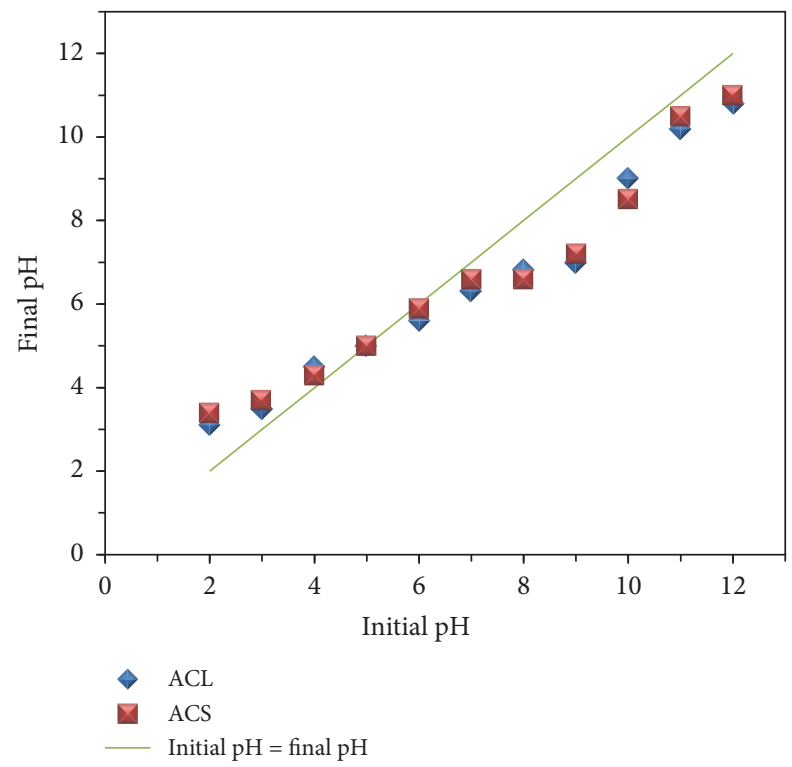

FIGURE 3: Determination of $\mathrm{pH}_{\mathrm{ZPC}}$ of ACL and ACS samples $(T=$ $25^{\circ} \mathrm{C}$ ).

latter sample (ACL), as the rate of adsorption is influenced by the fraction of surface area available for adsorption.

3.3. Adsorption Kinetics Study. The adsorption data obtained from the experiments on the effect of contact time were applied to three different kinetic models to study the kinetics of $\mathrm{Pb}(\mathrm{II})$ adsorption by ACL and ACS.

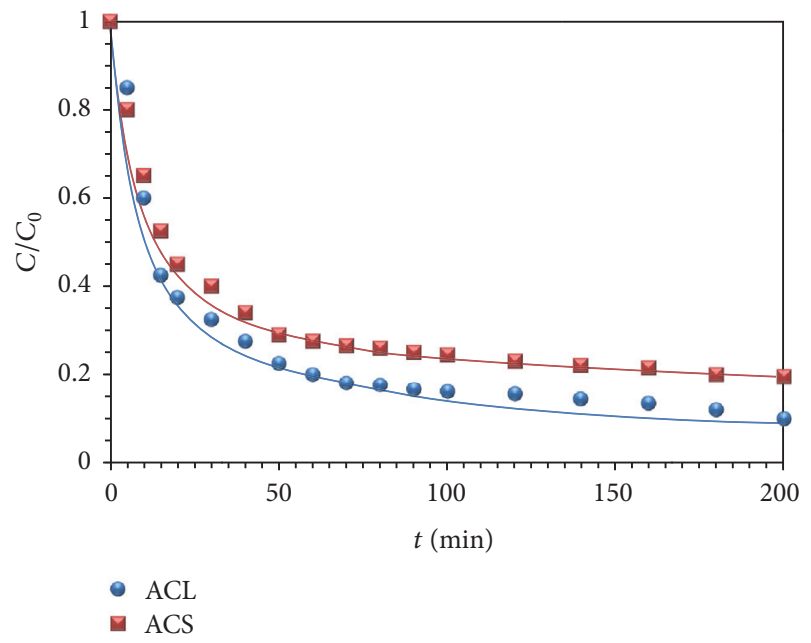

FIGURE 4: Effect of contact time on the adsorption of lead from aqueous solution, using ACS and ACL $\left(T=25^{\circ} \mathrm{C}\right)$.

Figures 5(a), 5(b), and 5(c) show the fitting in three models, pseudo-first-order, pseudo-second-order, and intraparticle diffusion model, respectively. The experimental and calculated parameters of the pseudo-first-order and pseudosecond-order models have also been summarized in Table 2.

According to the data presented in this table, the calculated linear regression correlation coefficients for the pseudofirst-order model are relatively small (Figure 5(a)), and the experimental $q_{e}$ values differ significantly from the values obtained from the linear plots. Therefore, it could be said 


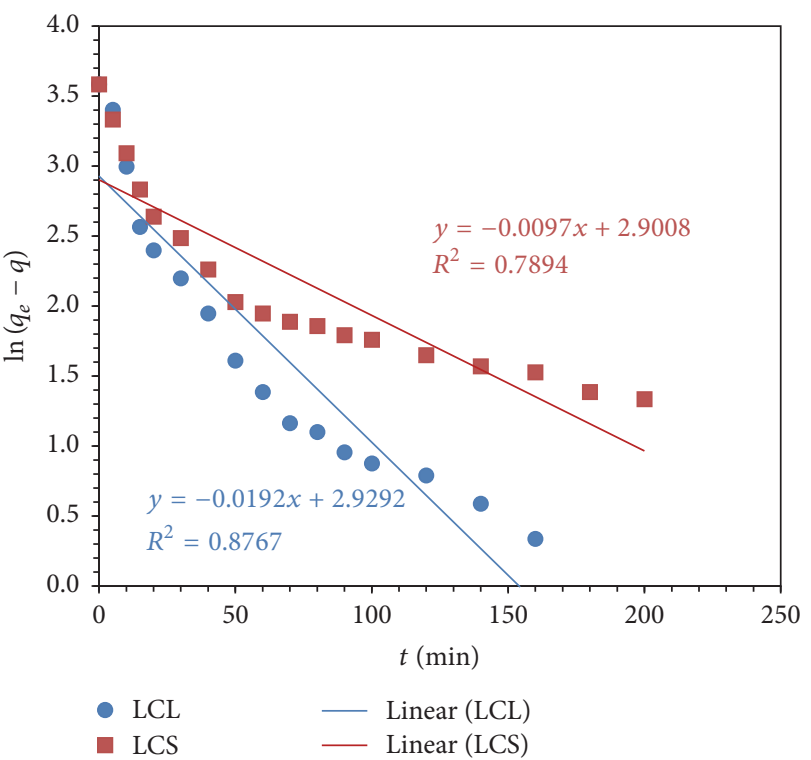

(a)

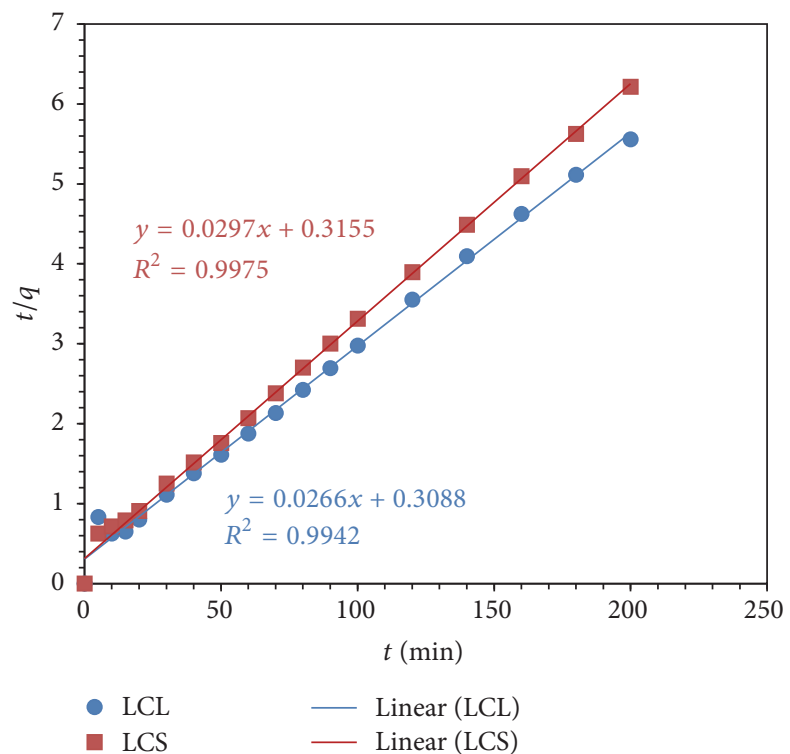

(b)

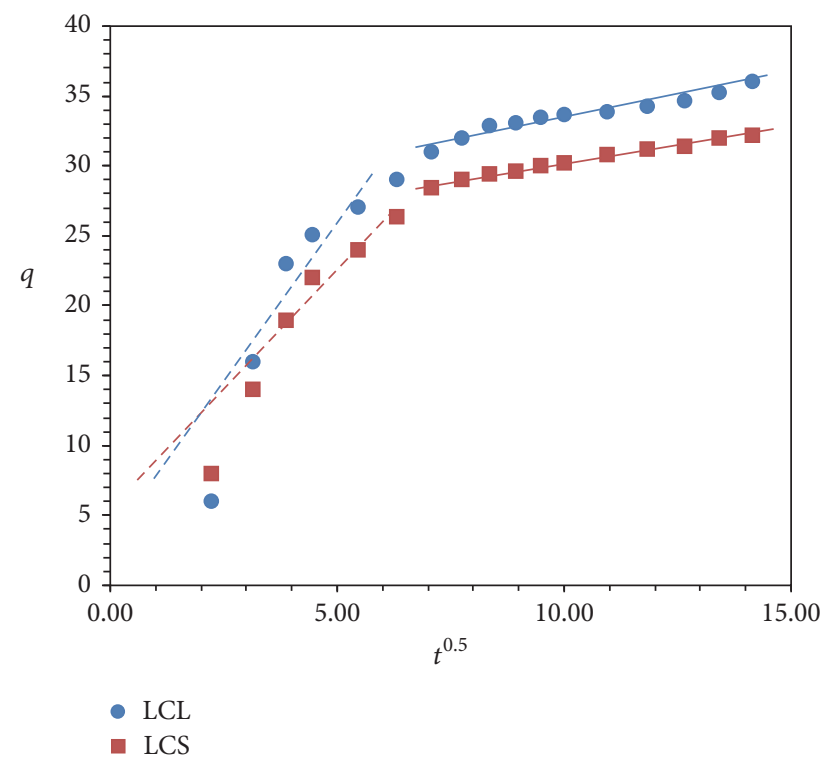

(c)

Figure 5: Kinetic analysis of adsorption capacity as a function of time $\left(\mathrm{min}^{-1}\right)$, using three different models: (a) pseudo-first-order, (b) pseudo-second-order, and (c) intraparticle diffusion model $\left(T=25^{\circ} \mathrm{C}\right)$.

that the pseudo-first-order equation is not suitable for lead adsorption on ACL and ACS system. As is evident from Figure 5(b) and Table 2, the fitting of experimental data to the pseudo-second-order model is reasonably good, $R^{2}>0.99$, and the calculated $q_{e}$ values agree well with the experimental values. This shows that $\mathrm{Pb}$ (II) ions uptake via both of the ACL and ACS can be estimated with the pseudo-secondorder kinetics model.

The intraparticle diffusion model is among the most commonly used techniques for the prediction of the ratecontrolling step of the adsorption process. Figure 5(c) shows $q$ versus $t^{0.5}$ plot for $\mathrm{Pb}(\mathrm{II})$ ions adsorption onto the ACL and ACS. The plot shows two distinct kinetic steps which suggest the existence of at least two stages in the $\mathrm{Pb}(\mathrm{II})$ ions sorption process. It is likely that, in the sharper first portion, the adsorbate ions get bound or anchored with the active sites on the adsorbent surface while the second step was governed by the rate of intraparticle diffusion. In the first stage, due to the larger adsorbent surface area of the ACL sample, the adsorption rate onto this adsorbent was considerably higher than that for ACS sample. Considering the second stage, again the computed intraparticle diffusion parameters show a higher adsorption rate constant for ACL as compared to ACS. The remarkably slow diffusion into the intrapores of the ACS 


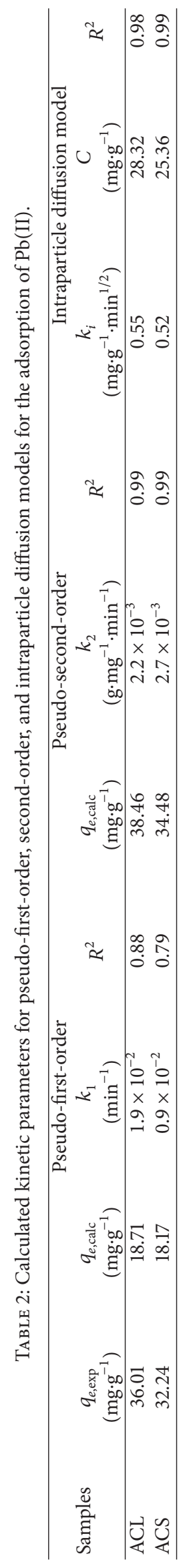




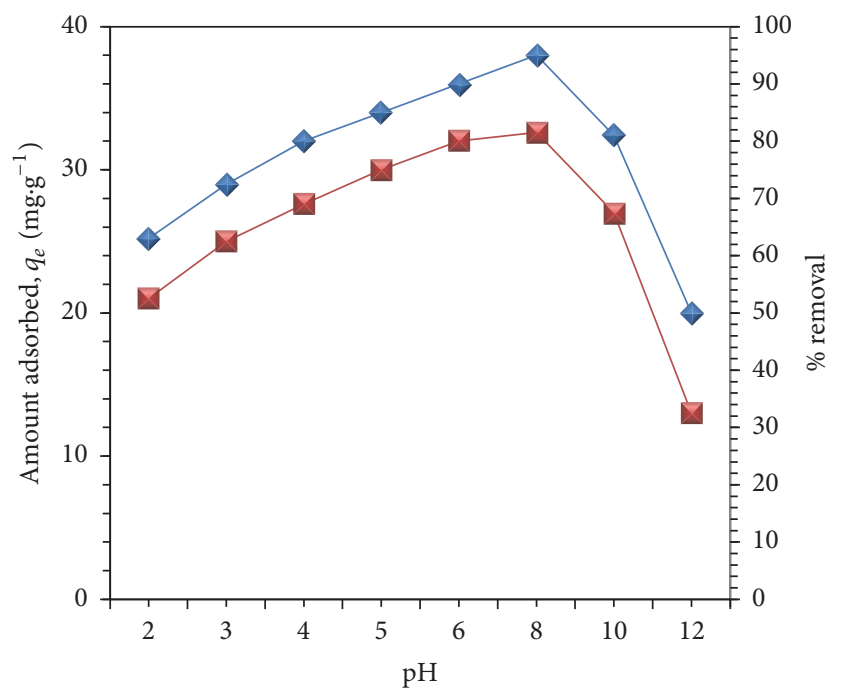

$-\mathrm{ACL}$
$-\mathrm{ACS}$

FIGURE 6: Effect of $\mathrm{pH}$ on the adsorption capacity and \% removal of ACL and ACS sample $\left(T=25^{\circ} \mathrm{C}\right)$.

samples may have been due to lack of microporosity in the sample that could have facilitated diffusion of adsorbate ions in the rate determination step.

3.4. Effect of $p H$. The $\mathrm{pH}$ of adsorbate solution determines the surface charge of adsorbents, the speciation of adsorbate species, and the degree of ionization and that is why it is one of the most important variables in adsorption investigations [5]. It is also directly related to precipitation conditions, particularly in the case of heavy metals, where it plays a critical role in the removal of heavy metal ions from aqueous solutions. The effect of solution $\mathrm{pH}$ on the $\%$ precipitation of the lead is shown in Figure 6. It was found that there is precipitation of the metal throughout the $\mathrm{pH}$ range examined. However, at $\mathrm{pH}>5.0$ over $30 \%$ precipitation was observed, which would modify the adsorption result if such $\mathrm{pH}$ values were applied in the tests. This precipitation occurs due to $\mathrm{Pb}$ (II) ion association with $\mathrm{OH}$-ions of the basic solution to form lead hydroxides. At $\mathrm{pH}<3.0$, it is possible that the lead is present in the form of $\mathrm{PbOH}^{+}$, even in small amounts, which may explain the low precipitation in this $\mathrm{pH}$ range.

The difference between the total removal percentage of $\mathrm{Pb}$ (II) ions and the percentage removed by precipitation yields the adsorption percentage of lead, which is also given in Figure 6. It shows an increase in the removal of lead ions with increases in solution $\mathrm{pH}$ up to 5 , after which a gradual and then fast decrease were observed up to $\mathrm{pH} 10$. Maximum lead removal values were obtained at $\mathrm{pH}$ values of 5-6. The reduced metal uptake witnessed at low $\mathrm{pH}$ values may have been due to excessive protonation $\left(\mathrm{H}^{+}\right.$ions) of the carbon surface, which render the adsorption of $\mathrm{Pb}$ (II) ions [37]. At higher $\mathrm{pH}$ values, the concentration of $\mathrm{H}^{+}$ becomes low, and the surface becomes negatively charged carbon surface (see Section 3.1 and Figure 3) that causes further attraction of metal cations. Nonetheless, at alkaline conditions, a decrease in adsorption was observed which is because of the formation of several hydroxide species by $\mathrm{Pb}$ (II) ions which are precipitated and lead to the decrease in free metal ions available in solution and [38] reported an optimum $\mathrm{pH}$ of 5 for lead adsorption. Bhattacharyya and Sharma obtained a good retention of lead in the $\mathrm{pH} 7$ and noted that at $\mathrm{pH}<4.5$ there was excessive protonation of the carbon surface, resulting in a decrease in the adsorption of $\mathrm{Pb}$ (II) [39]. Considering the interference due to precipitation during the adsorption experiments with $\mathrm{AC}$, the $\mathrm{pH}_{\mathrm{PZC}}$ value, and the lead speciation diagram, the $\mathrm{pH}$ selected for subsequent tests in this study was 5.0.

3.5. Adsorption Isotherms and Modeling of Isotherm Data. Figure 7 displays the experimental data of $\mathrm{Pb}(\mathrm{II})$ adsorption isotherms on both ACL and ACS at three different temperatures $\left(25,35\right.$, and $\left.45^{\circ} \mathrm{C}\right)$ and nonlinear fitting of Langmuir and Freundlich models on experimental values. Table 3 shows the model specific constants at different temperatures, which were calculated from the fitting parameters. The relative difference in adsorption amounts at different temperature shows that, with both the activated carbon samples, the adsorption increases with a decrease in temperature. It is likely due to increasing in surface energy of the activated carbon samples, which would render the interaction of adsorbing $\mathrm{Pb}$ (II) ions with the surface [40]. The Langmuir and Freundlich adsorption models were used for fitting the experimental data (Figure 7). A quick comparison in the fitting pattern shows that the Freundlich model shows better fitting on adsorption data by ACL. However, in contrast, ACS-adsorption data shows better fitting with Langmuir model and $q_{\max }$ calculated from this model $\left(37.93 \mathrm{mg} \cdot \mathrm{g}^{-1}\right)$ is close to $q_{\text {expt }}\left(37.6 \mathrm{mg} \cdot \mathrm{g}^{-1}\right)$ values. The application of the Langmuir model is based on the assumption that the binding of the adsorbate onto the surface of the adsorbent occurs primarily through a chemical reaction and that all sites have equal affinity for the metal. The Freundlich isotherm model is an empirical equation based on adsorption onto heterogeneous surfaces ( $\mathrm{Li}$ et al. 2010). Most assumptions related to the Langmuir model (such as adsorption onto a homogenous surface, with an identical fixed number of adsorption sites) are invalid for the heterogeneous surface of activated carbon. Thus, it is appropriate to use the Langmuir equation for qualitative and descriptive, rather than quantitative, purposes.

3.6. Regeneration and Reuse Study. Figure 8 shows a comparison in desorption\% of the lead with six different desorbing agents in both the samples. None of the desorbing solutions caused apparent physical alterations or impairment to the samples, enabling its reuse. For both the samples $\mathrm{HCl}$ showed maximum effectiveness, with approximately $66.1 \%$ and $55.6 \%$ removal from ACL and ACS, respectively. The efficiency of the rest of the desorbents follows a common order of $\mathrm{HNO}_{3}>\mathrm{H}_{3} \mathrm{PO}_{4} \gg \mathrm{NaOH}>\mathrm{NaCl}>\mathrm{H}_{2} \mathrm{O}$. The $\mathrm{H}^{+}$from an acidic medium may actively replace the metal ions ( $\mathrm{Pb}$ ion) adsorbed on the carbon. Therefore, considering these results the $\mathrm{HCl}$ was used as a desorbing agent because it is of low 
TABLE 3: Parameters of Langmuir and Freundlich adsorption models obtained from fitting of adsorption data at a different temperature.

\begin{tabular}{|c|c|c|c|c|c|c|c|}
\hline \multirow[b]{2}{*}{ Sample } & \multirow{2}{*}{$\begin{array}{c}\text { Temp } \\
\left({ }^{\circ} \mathrm{C}\right)\end{array}$} & \multicolumn{3}{|c|}{ Langmuir } & \multicolumn{3}{|c|}{ Freundlich } \\
\hline & & $\underset{\mathrm{mg} \cdot \mathrm{g}^{-1}}{q_{\max }}$ & $\begin{array}{c}b \\
\mathrm{~L} \cdot \mathrm{mg}^{-1}\end{array}$ & $R^{2}$ & $\begin{array}{c}K_{f} \\
\left(\mathrm{mg} \cdot \mathrm{g}^{-1}\right)\left(\mathrm{L} \cdot \mathrm{mg}^{-1}\right)^{1 / n}\end{array}$ & $1 / n$ & $R^{2}$ \\
\hline \multirow{3}{*}{$\mathrm{ACL}$} & 25 & 45.79 & 0.12 & 0.9639 & 13.92 & 0.23 & 0.995 \\
\hline & 35 & 42.08 & 0.07 & 0.9716 & 10.81 & 0.25 & 0.9948 \\
\hline & 45 & 38.08 & 0.06 & 0.9653 & 9.36 & 0.25 & 0.9896 \\
\hline \multirow{3}{*}{ ACS } & 25 & 37.93 & 0.19 & 0.999 & 14.74 & 0.18 & 0.9106 \\
\hline & 35 & 32.75 & 0.13 & 0.999 & 12.12 & 0.18 & 0.899 \\
\hline & 45 & 28.14 & 0.12 & 0.998 & 11.13 & 0.17 & 0.855 \\
\hline
\end{tabular}

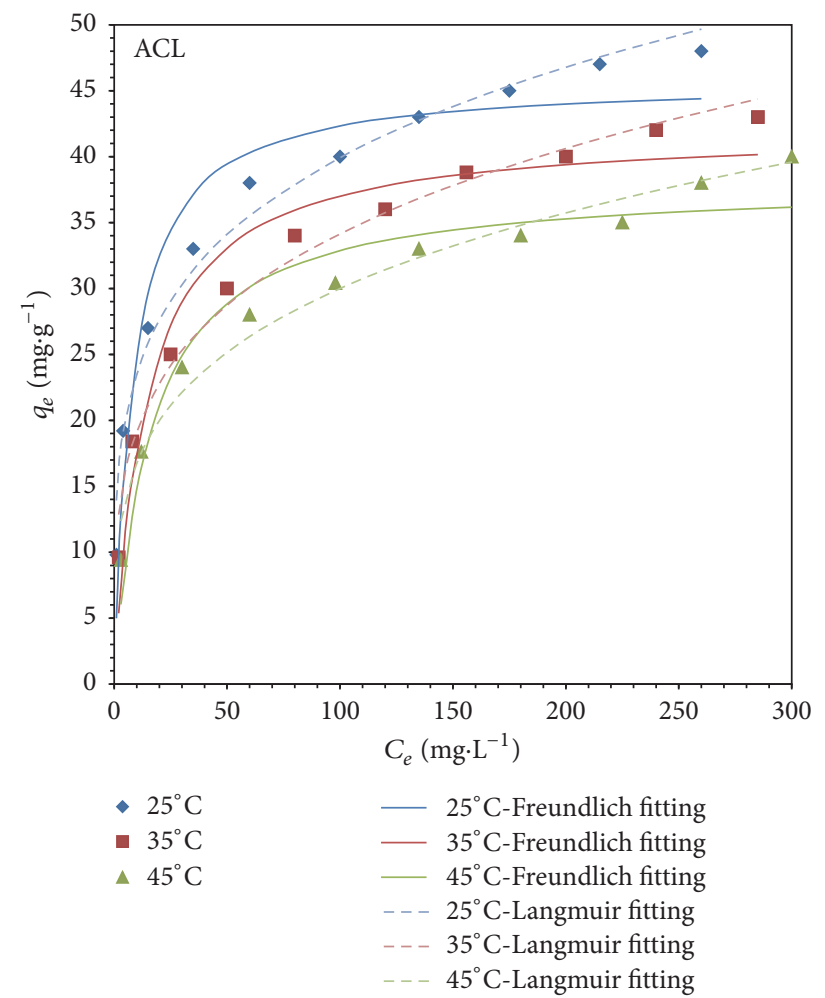

(a)

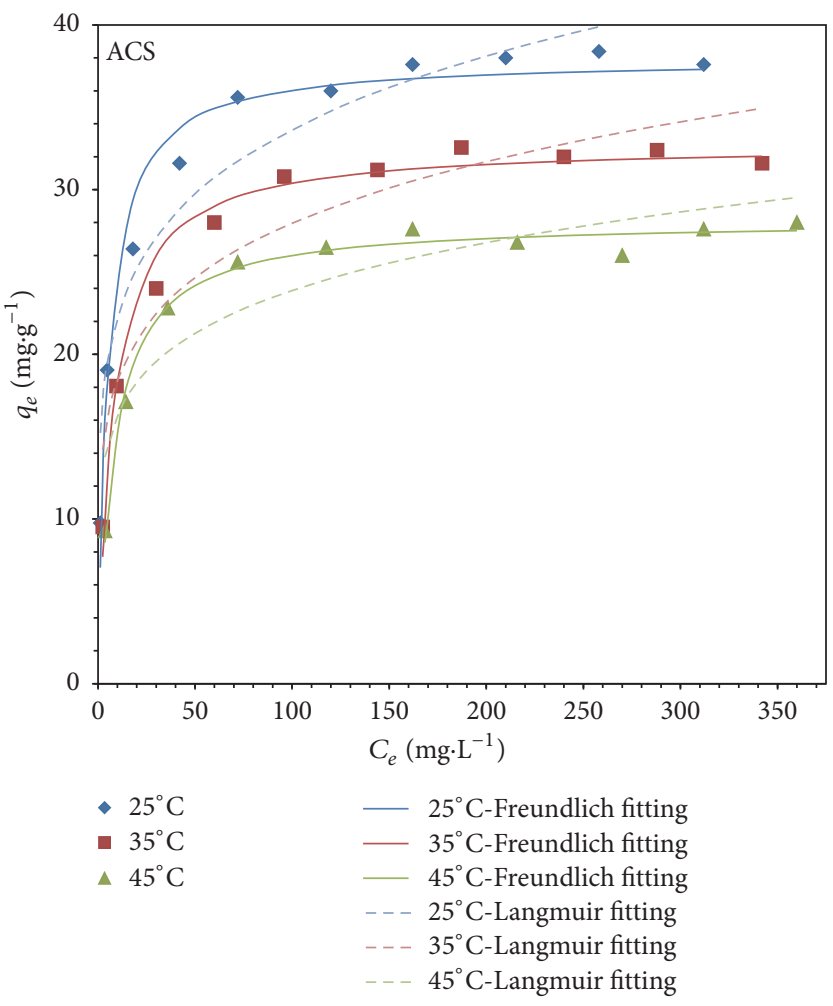

(b)

Figure 7: Adsorption isotherm of $\mathrm{Pb}(\mathrm{II})$ ions on ACL and ACS at different temperatures and fitting of adsorption data on Langmuir and Freundlich models.

cost compared to other materials and offers better desorbing efficiency.

The results of reuse experiments obtained from both activated carbon samples were of contrast to each other. The $\%$ of $\mathrm{Pb}$ (II) adsorption and desorption falls steeply in the case of ACL samples, which makes it almost unsuitable for reuse after two cycles (figure not given). On the other hand, the ACS sample shows reasonably good results of $\%$ adsorption and desorption up to four successive cycles; see Figure 9. It shows that during first cycle $90 \%$ adsorption and $66 \%$ desorption were achieved with respect to the value of $C_{0}=200 \mathrm{mg} \cdot \mathrm{L}^{-1}$. For the second, third, and fourth cycles $80 \%, 67.5 \%$, and $50 \%$ for adsorption and $56.2 \%, 40.7 \%$, and $20 \%$ desorption, respectively, were observed. The $50 \%$ loss in adsorption capacity during four cycles could be due to cumulative effect of the inadequate desorption. It may be crucial to use an acid solution with a higher strength or larger amounts of desorbent solutions.

In the view of sustainability, the desorbed lead from ACS samples could be reutilized and reverted to factories as a raw material, in spite of being deposited in sanitary landfills as waste. Electrolysis is one of the key processes for its recovery and can be useful to transform lead solution into the elemental lead (using stainless steel electrode).

3.7. Comparison of Adsorption Capacity with Other Adsorbents. The adsorption capacities of ACL and ACS were compared (Table 4) with other reported studies on activated 
TABLE 4: Comparison between adsorption capacities of several adsorbents, obtained from natural organic materials, for $\mathrm{Pb}(\mathrm{II})$ ions.

\begin{tabular}{|c|c|c|c|c|}
\hline & Adsorption capacity & & Equilibrium time & \\
\hline Sorbent ${ }^{*}$ & $\begin{array}{c}q_{\max } \\
\left(\mathrm{mg}^{-1} \mathrm{~g}^{-1}\right)\end{array}$ & Optimum pH & $\begin{array}{c}T \\
(\min )\end{array}$ & Reference \\
\hline Cashew nut shell AC & 28.9 & $6.0-6.5$ & 30 & [17] \\
\hline Hazelnut husk AC & 13.05 & 5.7 & 60 & [18] \\
\hline Coconut shell AC & 26.5 & 4.5 & 35 & [19] \\
\hline Apricot Stone AC & 22.85 & 4 & 300 & {$[20]$} \\
\hline Van apple pulp AC & 15.96 & 5 & 50 & {$[21]$} \\
\hline Polygonum orientale AC & 98.39 & 5 & 30 & {$[22]$} \\
\hline Pine cone AC & 27.53 & 5 & 60 & {$[23]$} \\
\hline Cow bone AC & 32.1 & 4 & 360 & {$[24]$} \\
\hline Dehydrated hazelnut husks carbon & 133.3 & 4.5 & 60 & {$[25]$} \\
\hline Hazelnut husks AC & 109.9 & 5 & 1200 & {$[26]$} \\
\hline ACL & 48.1 & $5.0-6.0$ & 180 & This study \\
\hline ACS & 37.6 & $5.0-6.0$ & 180 & This study \\
\hline
\end{tabular}

${ }^{*} \mathrm{AC}=$ activated carbon.

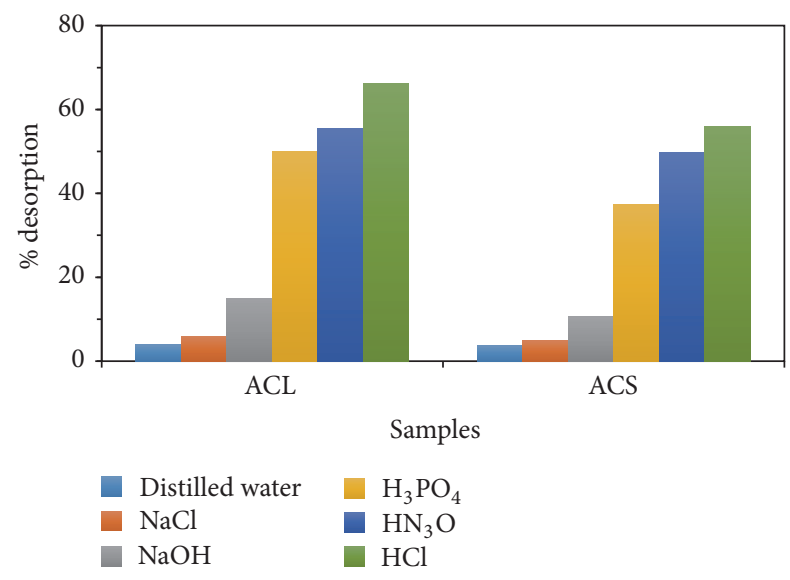

FIgURE 8: Lead desorption from activated carbon samples using several desorbent chemical agents $\left(T=25^{\circ} \mathrm{C}\right)$.

carbon for lead removal. These studies have used a variety of starting materials like nutshells, pulp, seeds, and animal bones for activated carbon preparation. The comparison shows that adsorption capacities of the present materials are better than some of the reported studies. It shows that Lantana camara L. can be used as a lucrative source of activated carbon.

\section{Conclusions}

The results of this study show that valorization of Lantana Camara L. can be achieved by converting it into an activated carbon with the moderate surface area, by using $\mathrm{H}_{2} \mathrm{SO}_{4}$ impregnation method. The compositional differences in leaf and stem of plant give rise to a difference in textural and surface properties of resulting activated carbon. Therefore, the surface area and adsorption capacity of activated carbon obtained from its leaf samples are higher than those from stem samples. The acid treatment increases the negative

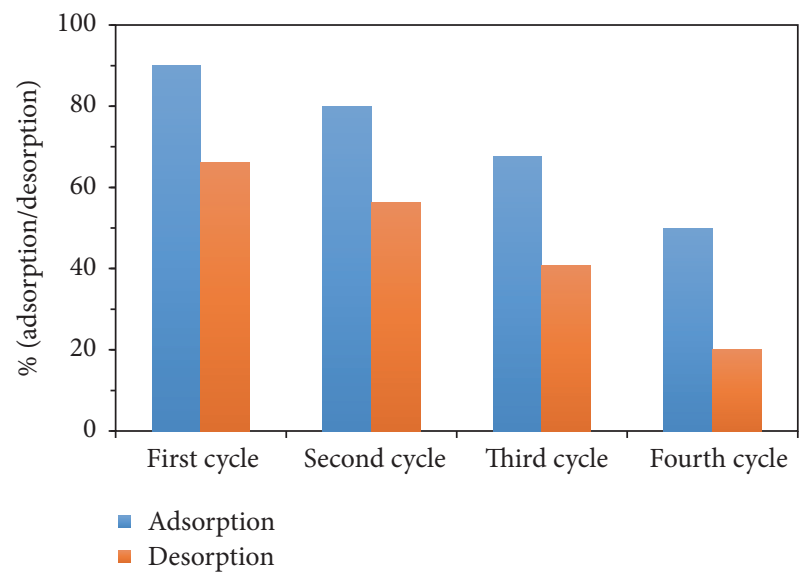

FIgURE 9: Percentage of $\mathrm{Pb}(\mathrm{II})$ adsorbed-desorbed per cycle $(T=$ $25^{\circ} \mathrm{C}$ ), with ACS sample.

charge on the surface in both the samples. Consequently, the $\mathrm{pH}$ becomes a critical factor in the lead adsorption, at $\mathrm{pH}$ $>$ 5.0. For both the activated carbon samples, the pseudosecond-order kinetic model best represented the adsorption kinetics data. ACL-adsorption equilibrium system was best described by Langmuir model, whereas ACS system was better explained by Freundlich model. The adsorbed lead on the samples can be efficiently desorbed with the help of $\mathrm{HCl}$. The reusability of ACL samples is not satisfactory as compared to ACS samples. Concluding this study, it may be mentioned that although ACS has $<12 \%$ less adsorption capacity compared to ACL, but it shows better reusability and thereby shows the better potential of a new low-cost adsorbent. This study opens the route to further studies where the selectivity of this Lantana camara L. based activated carbon can be investigated for other emerging pollutants like endocrine disruptors and pharmaceuticals. 


\section{Competing Interests}

The authors declare that they have no competing interests.

\section{Acknowledgments}

The authors acknowledge the financial support by School of Environment and Natural Resources, Doon University, Dehradun, and Department of Environmental Engineering, National Institute of Technology, New Delhi India.

\section{References}

[1] O. P. Sharma, H. P. S. Makkar, and R. K. Dawra, "A review of the noxious plant Lantana camara," Toxicon, vol. 26, no. 11, pp. 975-987, 1988.

[2] S. A. Bhagwat, E. Breman, T. Thekaekara, T. F. Thornton, and K. J. Willis, "A battle lost? Report on two centuries of invasion and management of Lantana camara L. in Australia, India and South Africa," PLoS ONE, vol. 7, no. 3, Article ID e32407, 2012.

[3] S. Raghu, O. O. Osunkoya, C. Perrett, and J.-B. Pichancourt, "Historical demography of Lantana camara L. reveals clues about the influence of land use and weather in the management of this widespread invasive species," Basic and Applied Ecology, vol. 15, no. 7, pp. 565-572, 2014.

[4] R. J. Fensham, "Land clearance and conservation of inland dry rainforest in north Queensland, Australia," Biological Conservation, vol. 75, no. 3, pp. 289-298, 1996.

[5] I. Ali and V. K. Gupta, "Advances in water treatment by adsorption technology," Nature Protocols, vol. 1, no. 6, pp. 26612667, 2007.

[6] S. Babel and T. A. Kurniawan, "Low-cost adsorbents for heavy metals uptake from contaminated water: a review," Journal of Hazardous Materials, vol. 97, no. 1-3, pp. 219-243, 2003.

[7] R. K. Gautam, P. K. Gautam, S. Banerjee et al., "Removal of tartrazine by activated carbon biosorbents of Lantana camara: kinetics, equilibrium modeling and spectroscopic analysis," Journal of Environmental Chemical Engineering, vol. 3, no. 1, pp. 79-88, 2015.

[8] C. R. Girish and V. Ramachandra Murty, "Mass transfer studies on adsorption of phenol from wastewater using Lantana camara, forest waste," International Journal of Chemical Engineering, vol. 2016, Article ID 5809505, 11 pages, 2016.

[9] A. D. Beattie, M. R. Moore, A. Goldberg, and W. T. Devenay, "Environmental lead pollution in an urban soft-water area," British Medical Journal, vol. 2, no. 5812, pp. 491-493, 1972.

[10] P. M. Félix, S. M. Almeida, T. Pinheiro, J. Sousa, C. Franco, and H. T. Wolterbeek, "Assessment of exposure to metals in lead processing industries," International Journal of Hygiene and Environmental Health, vol. 216, no. 1, pp. 17-24, 2013.

[11] Ö. Aktaş and F. Çeçen, "Adsorption and cometabolic bioregeneration in activated carbon treatment of 2-nitrophenol," Journal of Hazardous Materials, vol. 177, no. 1-3, pp. 956-961, 2010.

[12] C. Duran, D. Ozdes, A. Gundogdu, M. Imamoglu, and H. B. Senturk, "Tea-industry waste activated carbon, as a novel adsorbent, for separation, preconcentration and speciation of chromium," Analytica Chimica Acta, vol. 688, no. 1, pp. 75-83, 2011.

[13] J. E. Samad, S. Hashim, S. Ma, and J. R. Regalbuto, "Determining surface composition of mixed oxides with $\mathrm{pH}$," Journal of Colloid and Interface Science, vol. 436, pp. 204-210, 2014.
[14] B. H. Hameed, J. M. Salman, and A. L. Ahmad, "Adsorption isotherm and kinetic modeling of 2,4-D pesticide on activated carbon derived from date stones," Journal of Hazardous Materials, vol. 163, no. 1, pp. 121-126, 2009.

[15] N. M. Kovalchuk, O. K. Matar, R. V. Craster, R. Miller, and V. M. Starov, "The effect of adsorption kinetics on the rate of surfactant-enhanced spreading," Soft Matter, vol. 12, no. 4, pp. 1009-1013, 2016.

[16] N. Woitovich Valetti and G. Picó, "Adsorption isotherms, kinetics and thermodynamic studies towards understanding the interaction between cross-linked alginate-guar gum matrix and chymotrypsin," Journal of Chromatography B: Analytical Technologies in the Biomedical and Life Sciences, vol. 1012-1013, pp. 204-210, 2016.

[17] N. I. S. Tangjuank, J. Tontrakoon, and V. Udeye, "Adsorption of Lead(II) and Cadmium(II) ions from aqueous solutions by adsorption on activated carbon prepared from cashew nut shells," International Journal of Chemical, Molecular, Nuclear, Materials and Metallurgical Engineering, vol. 3, pp. 221-227, 2009.

[18] M. Imamoglu and O. Tekir, "Removal of copper (II) and lead (II) ions from aqueous solutions by adsorption on activated carbon from a new precursor hazelnut husks," Desalination, vol. 228, no. 1-3, pp. 108-113, 2008.

[19] M. Sekar, V. Sakthi, and S. Rengaraj, "Kinetics and equilibrium adsorption study of lead(II) onto activated carbon prepared from coconut shell," Journal of Colloid and Interface Science, vol. 279, no. 2, pp. 307-313, 2004.

[20] L. Mouni, D. Merabet, A. Bouzaza, and L. Belkhiri, "Adsorption of $\mathrm{Pb}$ (II) from aqueous solutions using activated carbon developed from Apricot stone," Desalination, vol. 276, no. 1-3, pp. 148-153, 2011.

[21] T. Depci, A. R. Kul, and Y. Önal, "Competitive adsorption of lead and zinc from aqueous solution on activated carbon prepared from Van apple pulp: study in single- and multi-solute systems," Chemical Engineering Journal, vol. 200-202, pp. 224236, 2012.

[22] L. Wang, J. Zhang, R. Zhao, Y. Li, C. Li, and C. Zhang, "Adsorption of $\mathrm{Pb}(\mathrm{II})$ on activated carbon prepared from Polygonum orientale Linn.: kinetics, isotherms, $\mathrm{pH}$, and ionic strength studies," Bioresource Technology, vol. 101, no. 15, pp. 5808-5814, 2010.

[23] M. Momčilović, M. Purenović, A. Bojić, A. Zarubica, and M. Randelovid, "Removal of lead(II) ions from aqueous solutions by adsorption onto pine cone activated carbon," Desalination, vol. 276, no. 1-3, pp. 53-59, 2011.

[24] M. A. P. Cechinel, S. M. A. G. Ulson De Souza, and A. A. Ulson De Souza, "Study of lead (II) adsorption onto activated carbon originating from cow bone," Journal of Cleaner Production, vol. 65, pp. 342-349, 2014.

[25] M. Imamoglu, A. Vural, and H. Altundag, "Evaluation of adsorptive performance of dehydrated hazelnut husks carbon for $\mathrm{Pb}(\mathrm{II})$ and $\mathrm{Mn}(\mathrm{II})$ ions," Desalination and Water Treatment, vol. 52, no. 37-39, pp. 7241-7247, 2014.

[26] M. Imamoglu, H. Şahin, Ş. Aydın, F. Tosunoğlu, H. Yılmaz, and S. Z. Yıldiz, "Investigation of $\mathrm{Pb}$ (II) adsorption on a novel activated carbon prepared from hazelnut husk by $\mathrm{K}_{2} \mathrm{CO}_{3}$ activation," Desalination and Water Treatment, vol. 57, no. 10, pp. 4587-4596, 2016.

[27] T. Yokoi, T. Tatsumi, and H. Yoshitake, " $\mathrm{Fe}^{3+}$ coordinated to amino-functionalized MCM-41: an adsorbent for the toxic oxyanions with high capacity, resistibility to inhibiting anions, 
and reusability after a simple treatment," Journal of Colloid and Interface Science, vol. 274, no. 2, pp. 451-457, 2004.

[28] R.-L. Tseng, "Physical and chemical properties and adsorption type of activated carbon prepared from plum kernels by $\mathrm{NaOH}$ activation," Journal of Hazardous Materials, vol. 147, no. 3, pp. 1020-1027, 2007.

[29] B. Streppel and M. Hirscher, "BET specific surface area and pore structure of MOFs determined by hydrogen adsorption at $20 \mathrm{~K}$," Physical Chemistry Chemical Physics, vol. 13, no. 8, pp. 32203222, 2011.

[30] R. K. Verma and S. K. Verma, "Phytochemical and termiticidal study of Lantana camara var. aculeata leaves," Fitoterapia, vol. 77, no. 6, pp. 466-468, 2006.

[31] N. R. Tesch, F. Mora, L. Rojas et al., "Chemical composition and antibacterial activity of the essential oil of Lantana camara var. moritziana," Natural Product Communications, vol. 6, no. 7, pp. 1031-1034, 2011.

[32] D. Angin, E. Altintig, and T. E. Köse, "Influence of process parameters on the surface and chemical properties of activated carbon obtained from biochar by chemical activation," Bioresource Technology, vol. 148, pp. 542-549, 2013.

[33] K. G. Sreejalekshmi, K. A. Krishnan, and T. S. Anirudhan, "Adsorption of $\mathrm{Pb}(\mathrm{II})$ and $\mathrm{Pb}$ (II)-citric acid on sawdust activated carbon: kinetic and equilibrium isotherm studies," Journal of Hazardous Materials, vol. 161, no. 2-3, pp. 1506-1513, 2009.

[34] A. Geethakarthi and B. R. Phanikumar, "Characterization of tannery sludge activated carbon and its utilization in the removal of azo reactive dye," Environmental Science and Pollution Research, vol. 19, no. 3, pp. 656-665, 2012.

[35] D. N. Shah, J. R. Feldkamp, J. L. White, and S. L. Hem, “Effect of the $\mathrm{pH}$-zero point of charge relationship on the interaction of ionic compounds and polyols with aluminum hydroxide gel," Journal of Pharmaceutical Sciences, vol. 71, no. 2, pp. 266-268, 1982.

[36] E. C. Scholtz, J. R. Feldkamp, J. L. White, and S. L. Hem, "Point of zero charge of amorphous aluminum hydroxide as a function of adsorbed carbonate," Journal of Pharmaceutical Sciences, vol. 74, no. 4, pp. 478-481, 1985.

[37] W. Liu, Y. Liu, Y. Tao, Y. Yu, H. Jiang, and H. Lian, “Comparative study of adsorption of $\mathrm{Pb}$ (II) on native garlic peel and mercerized garlic peel," Environmental Science and Pollution Research, vol. 21, no. 3, pp. 2054-2063, 2014.

[38] J. Anwar, U. Shafique, Waheed-uz-Zaman, M. Salman, A. Dar, and $\mathrm{S}$. Anwar, "Removal of $\mathrm{Pb}$ (II) and $\mathrm{Cd}(\mathrm{II})$ from water by adsorption on peels of banana," Bioresource Technology, vol. 101, no. 6, pp. 1752-1755, 2010.

[39] K. G. Bhattacharyya and A. Sharma, "Adsorption of Pb(II) from aqueous solution by Azadirachta indica (Neem) leaf powder," Journal of Hazardous Materials, vol. 113, no. 1-3, pp. 97-109, 2004.

[40] D. Mohan, P. Singh, A. Sarswat, P. H. Steele, and C. U. Pittman, "Lead sorptive removal using magnetic and nonmagnetic fast pyrolysis energy cane biochars," Journal of Colloid and Interface Science, vol. 448, pp. 238-250, 2015. 

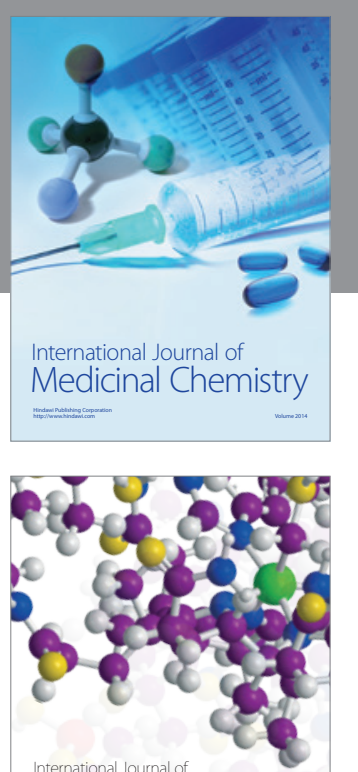

Carbohydrate Chemistry

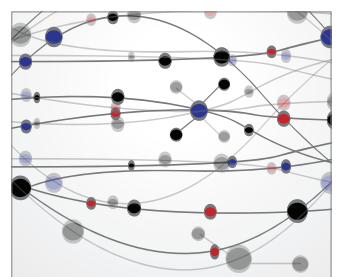

The Scientific World Journal
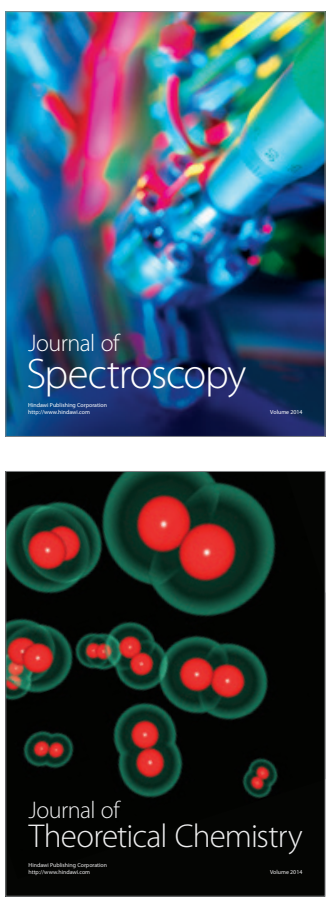
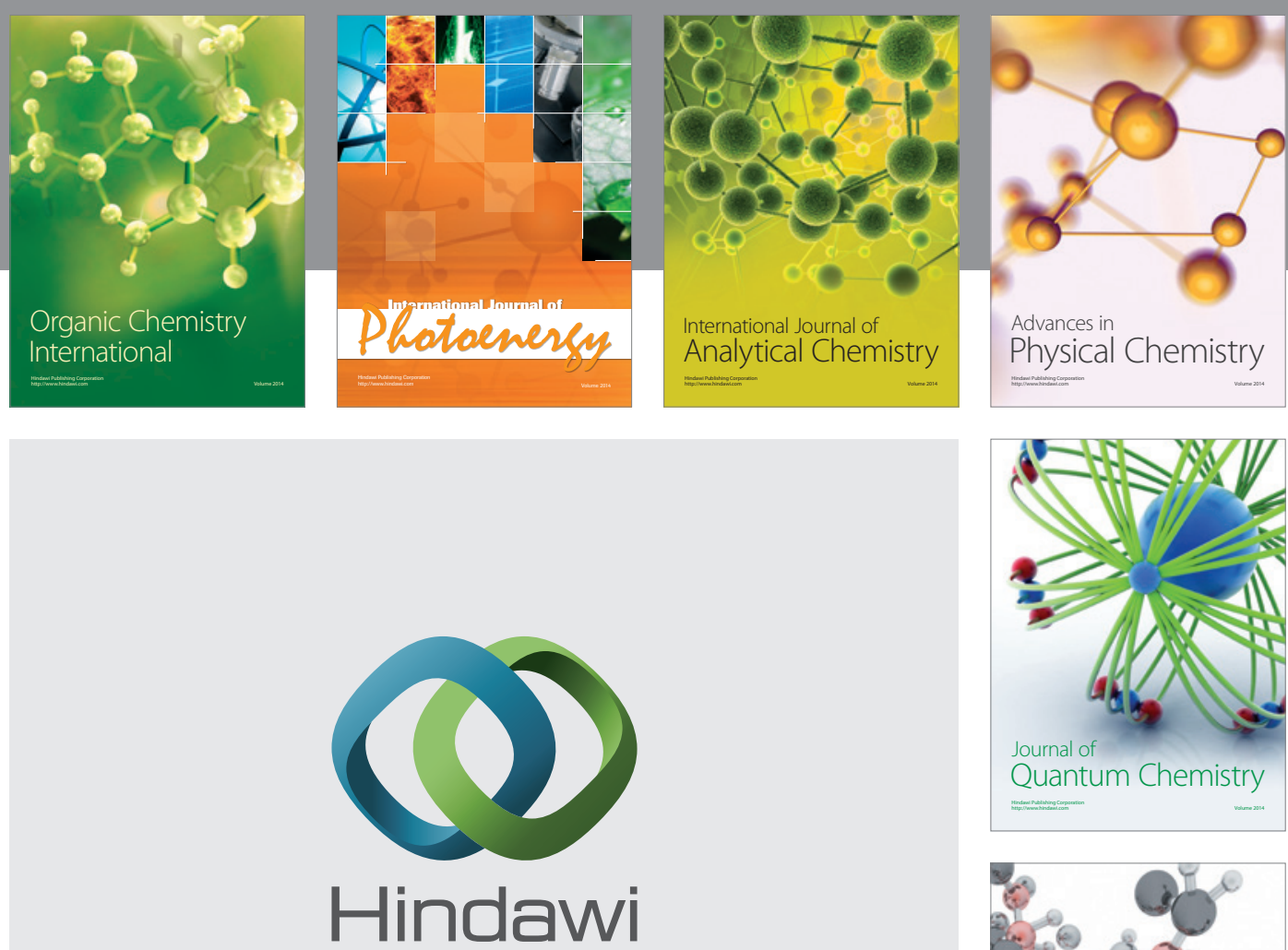

Submit your manuscripts at

https://www.hindawi.com

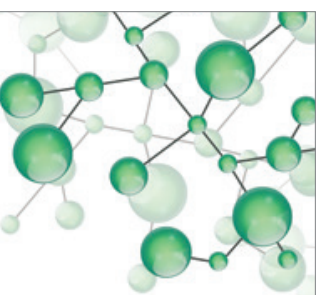

International Journal of

Inorganic Chemistry
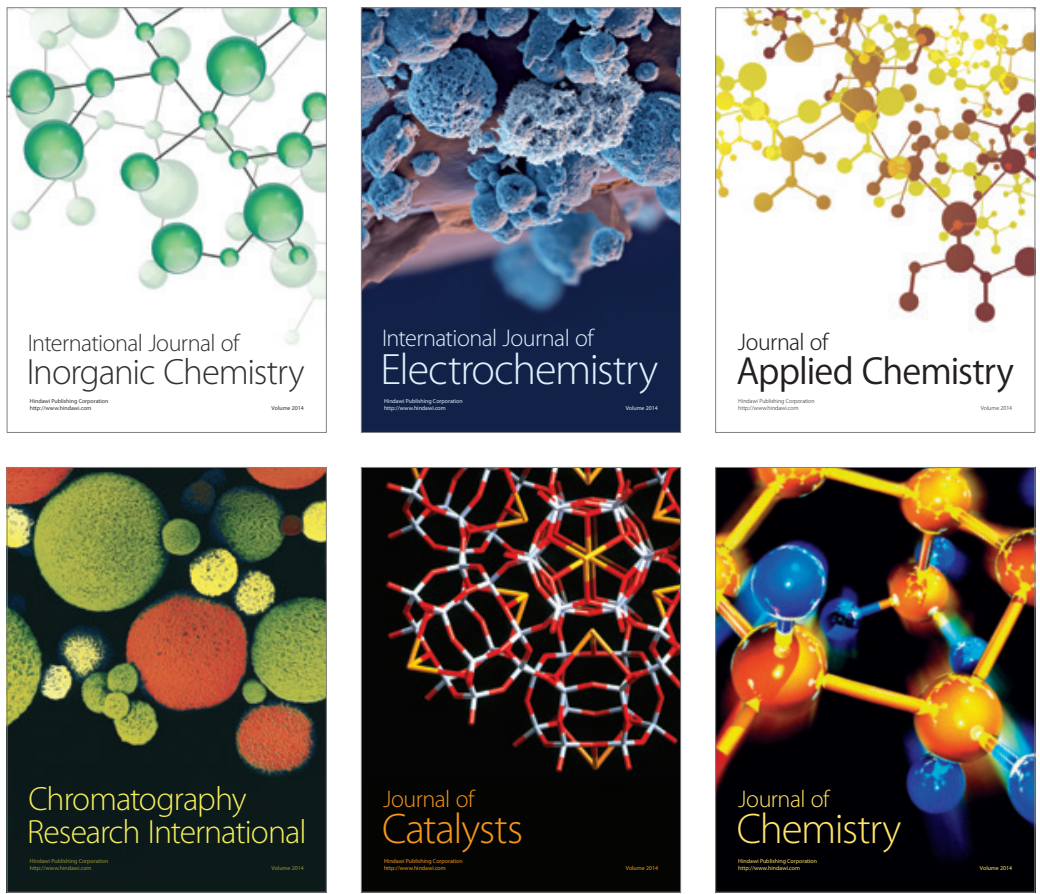

Journal of

Applied Chemistry
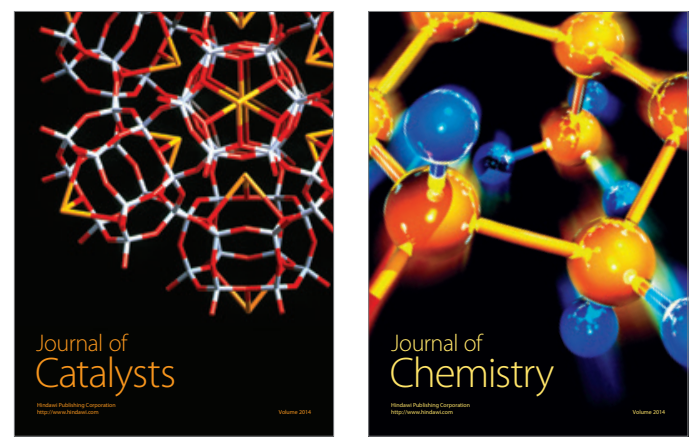
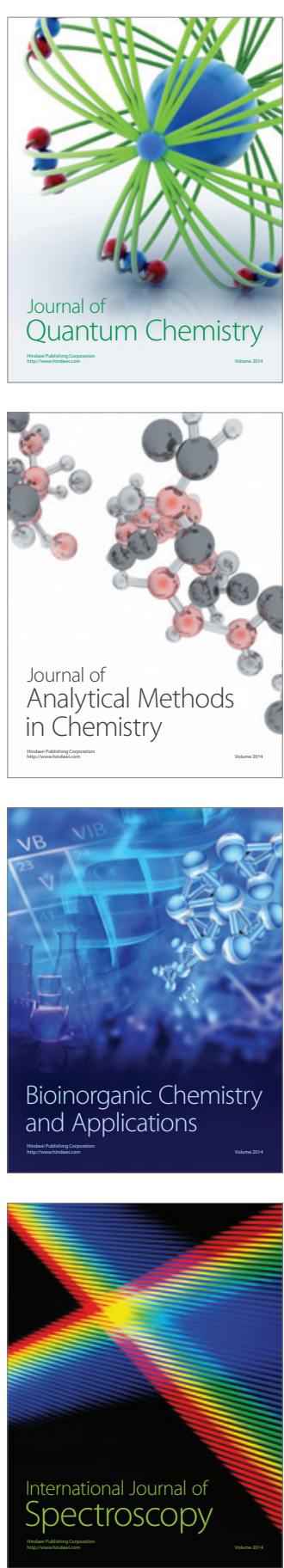